DOI: http://doi.org/10.21698/simi.2018.fp36

\title{
TRANSITION OF INCD ECOIND SIMCM TO THE REQUIREMENTS OF THE NEW STANDARDS ISO 9001: 20015 AND ISO 14001: 2015
}

\section{$\underline{\text { Virgil Criste }}$}

National Research and Development Institute for Industrial Ecology, 71-73 Drumul Podu Dambovitei, district 6, 060652, Bucharest, mmc@incdecoind.ro, Romania

\begin{abstract}
In National Research and Development Institute for Industrial Ecology has been developed a methodology for the transition of quality and environmental management systems to the requirements of ISO 9001 and ISO 114001 revised in 2015. The proposed methodology includes eight steps: organizational preparation, coordination team design, changes analysis, organizing courses, change management, risk assessment and system documentation, internal audit and management analysis. This methodology was applied for the transition of the quality and environmental integrated system (SIMCM) implemented in the institute and certified according to the requirements of the ISO 9001:2008 revisions and ISO 114001:2004 revision. The methodology has been successfully applied, the management analysis proposed the transition of the system to the requirements of the revised standards. Following the audit of the certification body, the system has been certified according to ISO 9001: 2015 and ISO 114001:2015, respectively.
\end{abstract}

Keywords: environment, quality, standard, transition

\section{Introduction}

The quality and environmental management systems have emerged in the industry in order to ensure the planned / projected quality of all products manufactured by an organization in conditions of environmental protection. Then these systems have been developed to ensure the demands of stakeholders in organization results.

The requirements for development and implementation of management systems are laid down in international standards developed by the International Standards Organization (ISO) Thus, were developed and published in 1987 families of ISO 9000 standards for quality management systems, respectively 14000 in 1996 for environmental management systems. These standards have been reviewed. The last revision took place in 2015.

This paper presents the methodology developed within the Management Systems Department for the transition of quality and environmental management systems, developed and implemented according to the requirements of the ISO 9001:2008 


\section{INTERNATIONAL SYMPOSIUM "THE ENVIRONMENT AND THE INDUSTRY", SIMI 2018, PROCEEDINGS BOOK}

and ISO 14001:2004 reference standards, to the requirements of the 2015 revised standards and the results of its application in practice.

\section{Materials and Methods}

The 2015 revision of the reference standards for quality and environmental management systems includes the following changes:

- brings two new important approaches: the organization's background together with stakeholders; the risk-based thinking;

- modify the structure of standards;

- introduces changes to terms.

\section{The context of the organization and the importance of stakeholders}

In order to assess his context, the organization must determine, monitor and control the internal factors (infrastructure, employee professional level, organizational culture) and external factors (social, economic, legislative) that are relevant to its purpose or affect or are affected by the organization's results, and the environmental conditions that may be affected by the organization or that may affect the organization's environmental performance (ISO 9001:2015).

The stakeholders and their relevant requirements for products, services, and environmental aspects generated by the organization's operation should also be determined.

\section{Risk-based approach}

This approach requires a systematic identification and analysis of existing risks and opportunities. The organization must determine the factors that could cause its processes and management system to deviate from planned outcomes and that may affect the product and service compliance and the ability to enhance customer satisfaction (Anghel \& Criste 2015). For the environment, the risks and opportunities relate to significant environmental aspects, compliance obligations, and product lifecycle perspectives. Environmental impacts that can be controlled and influenced at each stage of the product lifecycle are taken into account: procurement of raw materials, manufacturing, packaging, transport, delivery, consumer use, end of life cycle and final disposal (ISO 14001:2015). Organizations must make full use of emerging opportunities. Based on the analysis, actions are planned for treating the risks (and opportunities) to prevent or reduce unwanted effects.

\section{Structure of standards}

In order to facilitate the integration of the different management systems into one, a common structure of all standards, an identical base text and a set of 21 common terms and definitions have been established.

The new structure of standards includes 10 chapters (ISO 9001:2015):

- Application domain;

- Regulatory references;

- Terms and definitions;

- The organization context; 


\section{INTERNATIONAL SYMPOSIUM "THE ENVIRONMENT AND THE INDUSTRY", SIMI 2018, PROCEEDINGS BOOK}

- Leadership;

- Planning;

- Support;

- Operation;

- Performance evaluation;

- Improvement.

\section{Changes of terms (ISO 9001:2015)}

Management's responsibility becomes leadership. The decisions focus on trust, inspiration, attitude, behaviour, personal character.

The documentation becomes documented information and relates to communication of information, providing of evidence, transmission of knowledge, dissemination of experience, etc. There are no requirements for mandatory procedures or a management manual.

Supply becomes products and services supplied from outside.

Product becomes products and services.

Continuous improvement becomes improvement.

Organizational knowledge required for system and process operation.

For the transition of the integrated quality and environmental management system to the requirements of the new standards we have developed a methodology that takes place in eight stages:

- preparing the organization

- designation of the coordination team

- analysis of changes

- organizing trainings

- management of change

- risk assessment and system documentation

- internal audit

- management analysis

1. Preparing the organization

This requires acquisition of standard ISO 9001:2015 edition, identification and analysis of changes. It establishes a team of auditors who will perform the analysis and timeframe for the analysis and communicate to employees what is being done and why.

2. Designate the coordination team

The management of the organization designates by decision the team that will coordinate the project. Team members must have the necessary knowledge and authority to make decisions and allocate resources for the project.

3. Analysis of changes

The team of auditors performs a diagnostic analysis comparing the current SIMCM with the requirements of the new standards and establishes the necessary changes to be made to make the transition to the new requirements of the standards. For this, the team draws up and uses a checklist that includes the requirements of the new standards written in the form of questions. 


\section{INTERNATIONAL SYMPOSIUM "THE ENVIRONMENT AND THE INDUSTRY", SIMI 2018, PROCEEDINGS BOOK}

The diagnostic analysis is carried out in the form of an audit and includes the stages of an audit: planning the audit, conducting the audit and presenting the results through the audit report.

For each requirement (or set of requirements) the standard identifies the status of the current system.

The conclusions of the audit are summarized as a list comprising:

- the processes that comply with the standard and are documented.

- the processes that comply with the standard and need to be documented.

- the processes that do not comply with the standard and need to be redesigned.

- the processes imposed by the standard and not currently.

4. Organizing trainings

For effective implementation of the new standards requirements, the organization has to train staff to understand their role in achieving SMC performance and relevance. Thus, courses will be organized for:

- training the managers and the project and work team leaders

- training all employees on: what changes provide the new standards, what is the process approach, what is risk-based thinking, what is the impact on the workplace and how it can impact on the quality and the environment

- training the work teams so that all team members understand the standards in detail to do their job properly.

- training internal auditors with the new requirements of standards

5. Change management

In order to achieve the improvements associated with the changes, the organization should consider all types of changes that may occur. These changes can be generated, for example, in processes, documented information, equipment, employee training and supplier selection.

Change management includes:

5a. Planning the changes

Changes must be made in a planned and systematic manner. The organization must consider:

- the purpose of the changes and their potential consequences;

- the integrity of the quality management system,

- availability of resources;

- allocation or reallocation of responsibilities and authorities

Operational planning is reflected in the Design and Implementation Program.

5b. Designing and developing changes

During the design and development process are identified changes that will be implemented and controlled to ensure that there is no impact on product or service compliance, environmental performance, and compliance with legislation.

To determine priorities, the organization considers:

- consequences of the change

- likelihood of consequences

- impact on customers

- impact on stakeholders

Section Pollution Assessment \& Management Systems 307 


\section{INTERNATIONAL SYMPOSIUM "THE ENVIRONMENT AND THE INDUSTRY", SIMI 2018, PROCEEDINGS BOOK}

- impact on the environment

- impact on quality and environmental objectives

- the efficiency of processes that are part of the SIMCM

5c. Check for changes

Analysing and controlling changes in production or supply of services to the extent necessary to ensure continued compliance with the requirements.

The organization retains the documented information, describes the results of the review of the changes, establishes the persons authorized to modify it, as well as any necessary actions arising from the review.

6. Risk assessment and system documentation

Risk is an event that can affect your goals.

Once the processes are determined, once the changes are introduced, the risks and opportunities associated with these processes will also be identified.

Risks can be related to any element of the process, such as inputs, resources, people, activities, controls, measurements, outputs, etc.

The team will identify the risks for each process under review and propose control measures for risks that go beyond acceptable limits.

The methodology for identifying and assessing risks has been developed within the Managing Internal Control System. Identified risk management is done through the Risk Register (Criste 2011).

As the requirements for documenting the management system are reviewed, particular attention will be paid to identifying the documents that are required for the system and for the production or service processes.

For system documentation, work teams are created for each section of the standard. These are made up of employees and managers who will be responsible for the process.

While the coordination team is leading the project, the work teams will develop processes and establish documented information to meet the standard's requirements. The coordination team will review processes and documents and monitor the progress of work teams.

Although the new standards do not require documented procedures, we believe that existing procedures need to be kept by making the necessary revisions to meet the new requirements. A management manual, structured to the new standards, to describe the system is also useful.

7. Internal Audit

In order to find and correct the deficiencies in the management system before the certification audit, an internal audit is planned and performed, leaving time for the application of any corrective measures established as a result of the audit findings.

In order to perform the internal audit, the audit team will be trained. Auditors will use the checklist established for the diagnostic audit.

8. Analysis conducted by management

Management analysis is another key factor in getting a management system ready for the certification audit. In the meeting it analyses the information from the 


\section{INTERNATIONAL SYMPOSIUM "THE ENVIRONMENT AND THE INDUSTRY", SIMI 2018, PROCEEDINGS BOOK}

internal audit, the corrections and corrective actions proposed and undertaken, the information from the system monitoring and the results.

Additional corrective action can be taken to resolve problems and improve system performance. Records will be made and maintained.

\section{Results and Discussion}

The established methodology has been applied in the institute for transition of the SIMCM, certified according to ISO 9001:2008 respectively ISO 14001:2004, to the requirements of the 2015 revisions.

A project coordinating team was formed by two senior executives with experience in management systems and audit experience, one is responsible for the project. The responsible drafted the Strategic transition program of SIMCM to the requirements of the new standards.

According to the program, the team carried out the following activities:

- reviewed the changes made to the two standards and prepared the Checklist according to the requirements of the new standards.

- carried out an internal audit to determine the status of the current system against each requirement of the revised reference standards. The results of the audit were presented in the Audit Report.

- developed two course supports: ISO 9001:2015 and ISO 14001:2015 Changes in requirements and implementation for training the auditors and Transition of ISO 9001:2008 to ISO 9001:2015 and ISO 14001:2004 to ISO 14001:2015 for staff awareness on SIMCM transition to the new standards.

- organized two courses with developed course support: one for auditors training and one for training quality-environment compartments responsible

- identified the environmental risks, the risks to the achievement of environmental objectives and environmental compliance risks, established the risk management actions and control measures and completed the Risk Register.

- reviewed the SIMCM documentation as follows: a new management manual was developed on the structure of the new standards, the system and working procedures were revised in line with the requirements of the new standards.

- has conducted an internal audit to prepare the certification system

- was conducted a management analysis in which were discussed the results and was decided the SIMC transition to the requirements of the revised standards

\section{Conclusions}

The transition methodology of SIMCM to the requirements of the ISO 9001:2015 and ISO 14001:2015 standards was successfully applied in the institute because, after the management analysis, was decided the transition of the system and the proposal to certify it at the first surveillance audit of SIMCM. 


\section{INTERNATIONAL SYMPOSIUM "THE ENVIRONMENT AND THE INDUSTRY", SIMI 2018, PROCEEDINGS BOOK}

Following the audit of the QS CERT certification body in April 2017, the system obtained the ISO 9001:2015 and ISO 14001:2015 conformity certificates, as shown in Figure 1.

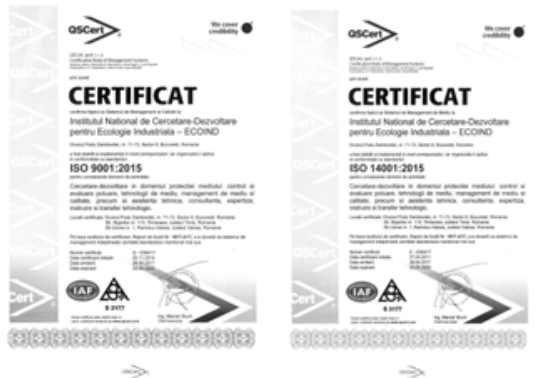

Figure 1. Certificates of conformity

At present, the methodology is part of the Management Systems Department portfolio and is used in consulting. The methodology was used in the consultancy offered to SC ISAF SA in a contract concluded within the project Promotion, identification and realization of partnerships for transfer of knowledge in the field of industrial ecology, in the Competitiveness Operational Program competition.

\section{Acknowledgements}

The study was carried out whithin the Romanian Nucleu Programme, Project PN 09-13 0416 Transition methodology of quality management systems to the new requirements for the risk based assessment approach on the organization's processes and PN 16250403 Transition of environmental management systems to the new requirements of the ISO 14001:2015 standard and its integration with the quality management system according to ISO 9001:2015

\section{References}

Anghel, A \& Criste, V 2015, The transition of the quality management systems to the new requirements regarding the approach based on the risk assessment in the organization's processes, International Symposium The Environment and The Industry, National Research and Development Institute for Industrial Ecology, Bucharest, pp. 138-144.

Criste, V 2011, Managing Internal Control System of the National Research and Development Institute for Industrial Ecology.

ISO 9001:2015 Quality management systems. Requirements.

ISO 14001:2015 Environmental management Systems. Requirements with guidance for use. 